\title{
Demonstração do fluxo de caixa: as controvérsias do conteúdo normativo do Pronunciamento Técnico n ${ }^{\circ}$ 03/08
}

\author{
João Alberto de Arruda (Coordenador) ${ }^{1}$
}

\section{Resumo}

As exigências do mercado interno e externo fizeram com que a partir de 2002, mudanças ocorressem na legislação societária brasileira especialmente, na tentativa de promover a elaboração de normas brasileiras em consonância com os padrões internacionais de contabilidade adotados nos principais mercados de valores mobiliários. Dentre as alterações mais relevantes destacam-se as promovidas na Lei 6.404/76 - Lei das Sociedades por ações, pelas Leis 11.638/07 e 11.944/09, Dentre as mudanças, ocorreu a substituição da Demonstração das Origens e Aplicações de Recursos DOAR - pela Demonstração do Fluxo de Caixa (DFC). Com isso, o Comitê de Pronunciamentos Contábeis (CPC) foi obrigado a precipitar o início das discussões e da edição dos pronunciamentos. Decorrem disso dúvidas em relação aos procedimentos de elaboração quanto ao alcance e utilidade das informações geradas pelo DFC. O estudo pretendeu responder: à seguinte questão: a obrigatoriedade da divulgação da DFC oferece melhores informações que as publicadas até então? O estudo teve como objetivo, verificar se a Demonstração do Fluxo de Caixa contribui efetivamente com a produção e apresentação de informações contábeis úteis e transparentes para os usuários das entidades. O estudo permitiu concluir que o conteúdo normativo do Pronunciamento Técnico CPC 03/08 - Demonstração de Fluxos de

1 Contador, Mestre em Administração contábil e financeira e Docente do Curso de Ciências Contábeis do UniCEUB.

Foram colaboradores neste estudo os Acadêmicos do Curso de Ciências Contábeis/UniCEUB:

Ádlas Dias Conrado RA 2085012/0;

André Luiz Benite RA 2085774/3;

Davisson Costa Barbosa RA 2086080/1;

Eleusa Pereira Feitosa RA 2098125/8;

Erika Carvalho Silva RA 2094181/5;

Hyago Rabelo Cavalcante RA 2085014/8;

Igor Vial Alvarenga RA 2085988/3;

Mateus Willig Araujo RA 2094841/5 
Caixa - é uma tradução com algumas pequenas alterações do IAS 7 - Demonstração dos Fluxos de Caixa; que na substituição da DFC pela DOAR mostrou não houve discussão suficiente para prover os usuários das melhores informações contábeis, úteis e transparentes. Houve a possibilidade de reunir as melhores características da DOAR e da DFC em um só Pronunciamento Técnico, que não foi aproveitado.

Palavras-chave: Fluxo de caixa. Informações úteis. Situação financeira.

\section{Introdução}

Há décadas, os estudiosos da área contábil no Brasil promovem e estimulam a discussão sobre a revisão e adequação das diferentes concepções, métodos, técnicas e, procedimentos contábeis em decorrência das exigências do mercado, da globalização e da legislação vigente.

O governo brasileiro é que, historicamente determina as regras internas e externas na realização dos negócios. A economia brasileira é regulada e controlada pelo governo nos seus diferentes aspectos, desde os mais singulares aos mais complexos. Este impõe normas de fiscalização, determina as formas que devem ser realizadas e registradas, e demonstradas as operações mercantis, os critérios de apuração dos resultados, a incidência ou não de tributos, a concessão de incentivos imposição de restrições aos setores produtivos nacionais, assim como, as formas de convivência com o mundo empresarial externo.

Uma significativa ação da classe contábil, buscando tornar relevante, ativa e efetiva a participação institucional da profissão, ocorreu em 2005, com a criação do Comitê de Pronunciamentos Contábeis - CPC, pela Resolução CFC No 1.055/05, como objetivo de elaborar, revisar, atualizar e melhorar o conteúdo das normas, que afetam direta e indiretamente a contabilidade:

[...] o estudo, o preparo e a emissão de Pronunciamentos Técnicos sobre procedimentos de Contabilidade e a divulgação de informações dessa natureza, para permitir a emissão de normas pela entidade reguladora brasileira, visando à centralização e uniformização do seu processo 
de produção, levando sempre em conta a convergência da Contabilidade Brasileira aos padrões internacionais (CONSELHO FEDERAL DE CONTABILIDADE, 2005).

Já as alterações promovidas na Lei 6.404/76 - Lei das Sociedades por Ações -, pelas Leis 11.638/07 e 11.941/09, fizeram com que o CPC precipitasse as discussões e a edição dos pronunciamentos, que permitissem adequar às normas contábeis como passou a prescrever o art. 177, $\$ 5^{\circ}$, da Lei 6.404/76, com redação dada pela Lei 11.638/07:

As normas expedidas pela Comissão de Valores Mobiliários a que se refere o $\$ 3$ o deste artigo deverão ser elaboradas em consonância com os padrões internacionais de contabilidade adotados nos principais mercados de valores mobiliários.

A partir das alterações da lei, os órgãos reguladores foram obrigados a buscar a convergências das normas nacionais às internacionais, isto dificultou a oferta aos usuários de um cronograma para discussão dos aspectos normativos.

A edição dos Pronunciamentos técnicos e as orientações e interpretações técnicas foram bem sucedidas em relação à edição e ajuste dos instrumentos existentes, ao ponto de até 2009, terem sido, na sua maioria, convertidos em normas pelos agentes reguladores, objetivando a consonância com a convergência com os padrões internacionais.

Há dúvidas em relação à extensão dos procedimentos que envolvem os critérios que devem ser utilizados na aplicação das novas regras, necessários à elaboração da Demonstração do Fluxo de Caixa - DFC, já que o prazo utilizado para as discussões destas, foi limitado, insuficiente para oferecer esclarecimentos e, ainda, as publicações e eventos sobre o assunto também se apresentam reduzidos para suprir a demanda. Diferentemente dos estudos que foram feitos nos EUA, na década de 60, sobre o mesmo assunto, pela necessidade de adequação dos demonstrativos, em função do crescimento do mercado de capitais americano.

Essa dificuldade de compreensão se observa de forma acentuada no meio universitário, especialmente, pelo número reduzido de treinamentos e de material didático que subsidie o docente em sua educação continuada. 
A DFC era reivindicada, por profissionais, autores renomados, estudiosos e grandes empresas brasileiras, em decorrência do entendimento de que se trata de um relatório contábil, essencialmente financeiro, adotado pelos países mais evoluídos. Em nome da convergência às normas internacionais alguns estudiosos já consideravam um avanço se o Brasil a adotasse.

O estudo pretende responder a seguinte indagação: o conteúdo normativo do Pronunciamento técnico 03/08, permite a divulgação da DFC com informações de qualidade?

Na expectativa de responder essa questão, o estudo teve como objetivo, verificar se as normas sobre a DFC possibilitam a produção e apresentação de informações contábeis úteis e de melhor qualidade para os usuários das entidades do que as produzidas pela DOAR.

Deve-se entender por informações contábeis úteis a concepção adotada pelo Pronunciamento Técnico CPC 03, de 13/07/2008, que trata da Demonstração dos Fluxos de Caixa, como segue:

As informações dos fluxos de caixa de uma entidade são úteis para proporcionar aos usuários das demonstrações contábeis uma base para avaliar a capacidade de a entidade gerar caixa e equivalentes de caixa, bem como suas necessidades de liquidez. As decisões econômicas que são tomadas pelos usuários exigem avaliação da capacidade de a entidade gerar caixa e equivalentes de caixa, bem como da época e do grau de segurança de geração de tais recursos

Este estudo foi desenvolvido com a participação dos alunos por meio de pesquisa bibliográfica com coleta dos dados realizadas em revistas, periódicos, livros, tendo como fonte principal o Pronunciamento Técnico $n^{\circ} 03 / 08$, do Comitê de Pronunciamentos Contábeis (CPC)- e normas dele decorrentes aprovadas pelo Conselho Federal de Contabilidade e pelos órgãos reguladores.

Tem como resultados esperados: o de propor um referencial que sirva como fonte de consulta aos acadêmicos de Ciências Contábeis e áreas afins, nas ativi- 
dades escolares; e reduzir as dificuldades na compreensão do teor normativo que norteiam, delimitam e definem as técnicas e procedimentos de elaboração da Demonstração do Fluxo de Caixa, suas implicações e extensão em relação às informações úteis aos usuários.

O estudo apresenta no anexo, simulação ilustrativa compilada do Apêndice do Pronunciamento Técnico $n^{\circ} 03 / 08$, não discute os procedimentos de sua elaboração, busca apenas mostrar e entender as controvérsias da norma e as implicações dos aspectos normativos na compreensão das exigências

\section{A evolução das normas brasileiras}

O crescimento do mercado brasileiro de valores mobiliários, promoveu alterações na Lei $n^{\circ}$ 6.404, de 15 de dezembro de 1976, que dispõe sobre as Sociedades por Ações, e na Lei no 6.385, de 7 de dezembro de 1976, que dispôs sobre o mercado de valores mobiliários e criou a Comissão de Valores Mobiliários inicialmente pela Lei 10.303, de 31 de outubro de 2001 e depois pelas Leis no 11.638/07 e 11.941/09.

Dentre as mudanças implementadas, está a obrigatoriedade das demonstrações financeiras das companhias abertas observarem as normas expedidas pela Comissão de Valores Mobiliários e que estas devem ser elaboradas em consonância com os padrões internacionais de contabilidade adotados nos principais mercados de valores mobiliários. Isso permite que as companhias fechadas possam também observar essas normas.

Em relação aos impactos da reformulação das leis, Ramon (2008, p. 18) antecipa os possíveis efeitos e destaca as vantagens que as mudanças podem trazer para o Brasil:

Maior transparência e credibilidade perante os investidores e o mercado em geral;

Modernização das práticas contábeis para atender às demandas do mercado; 
Redução de custos e maior facilidade na captação de recursos;

Ganhos de eficiência decorrentes da melhor qualidade de informação;

Aprimoramento da governança e dos controles internos; Equidade e facilidade de comparação entre empresas concorrentes;

Facilitação dos processos de fusão e aquisição de empresas; Melhor preparação da empresa para a hipótese de ser vendida;

Estímulo à qualificação dos profissionais de contabilidade.

Há uma expectativa positiva com os resultados que poderão advir das mudanças e uma evidente preocupação dos órgãos normativos com os interesses econômicos dos usuários, especialmente, os investidores externos, e com a capacidade das empresas nacionais produzirem informações úteis, transparentes, confiáveis e que possam ser comparadas com as geradas em outros países.

\section{As exigências da demonstração do fluxo de caixa}

A Lei das sociedades por Ações, Lei 6.404/76, de 15 de dezembro de 1976, no seu Art. 176, IV, - tornou obrigatória a elaboração da Demonstração das Origens e Aplicações de Recursos - DOAR, que deveria "indicar as modificações na posição financeira da companhia, [...]” (BRASIL, 1976).

Em abril de 1999, o Instituto dos Auditores Independentes do Brasil (IBRACON), editou a Norma e Procedimentos de Contabilidade (NPC) $n^{\circ} 20$, que regulamentou o a Demonstração do Fluxo de Caixa, no âmbito de sua competência.

Santos e Lustosa, discutiram, exaustivamente, nos Cadernos Temática Contábil dos Boletins IOB n 5, 6, 7 e 13 de 1988, diferentes aspectos do Fluxo de Caixa, destacando na sua adoção, em função das dificuldades de entendimento da DOAR pelos usuários:

O fato de não ser uma demonstração puramente financeira, de ter dependência de critérios de avaliação de estoques, de criação e apropriação das despesas antecipadas, e de estar 
ligada a um conceito abstrato (capital circulante líquido, por ser diferença algébrica de ativo e passivo circulante, diz respeito a um número, a um valor aritmético que em si mesmo é abstrato; concretos são o ativo e o passivo circulantes, mas sua diferença é um valor de natureza mais abstrata, difícil de ser entendido por quem não for bastante versado no ramo da contabilidade e das finanças), fazem da DOAR uma demonstração de pouca utilização prática. (SANTOS E LUSTOSA, 1988)

O Manual de contabilidade das sociedades por ações Fipecafi (2010, p.8) assim caracteriza a DOAR:

Essa demonstração procura evidenciar as origens de recursos que ampliam a folga financeira de curto prazo (ou o capital circulante líquido, numa linguagem mais técnica) e as aplicações de recursos que consomem essa folga.

Prossegue, Fipecafi (2010, p. 9) em relação à DFC, “A Demonstração dos Fluxos de Caixa visa mostrar como ocorreram às movimentações de disponibilidades em um dado período de tempo."

A substituição da Demonstração das Origens e Aplicações de Recursos (DOAR), pela Demonstração dos Fluxos de Caixa (DFC) efetivamente se deu com as alterações promovidas pelas Leis no 11.638/07 e 11.941/09 que, modificaram o Inciso IV do Art. 176 da Lei 6.404/76.

A Norma Internacional em que se inspirou e a que se refere o Pronunciamento Técnico - CPC nº 03 - é o IAS 7 - Demonstração dos Fluxos de Caixa, que baseou no Financial Accounting Standard - FAS 95: Statement of Cash Flows (Demonstração de Fluxo de Caixa), que só admite como componente dos fluxos as transações que tenham efeitos no caixa do período isto é, que tenham efetivamente representado entrada ou saída de dinheiro.

A tradução do IAS 7 -, transformou-se em minuta do Pronunciamento Técnico CPC 03/08 - Demonstração de Fluxos de Caixa - sendo colocada em discussão em audiência pública, pelo Comitê de Pronunciamentos Contábeis (CPC), em 2008. 
Em decorrência das alterações promovidas, em 2008, foi editado o Pronunciamento Técnico CPC 03/08, de 13/06/2008, que trata da Demonstração dos Fluxos de Caixa obriga sua apresentação como parte integrante das demonstrações contábeis. Enuncia Técnico CPC 03/08 que:

As informações dos fluxos de caixa de uma entidade são úteis para proporcionar aos usuários das demonstrações contábeis uma base para avaliar a capacidade de a entidade gerar caixa e equivalentes de caixa, bem como suas necessidades de liquidez.

Convém destacar o comentário às "sérias distorções que esse procedimento pode causar nas análises futuras das movimentações de caixa”, feitos por Santos e Lustosa (1999 apud MARTINS, Bol IOB 32, p. 302), como seguem: "o Balanço e a Demonstração do Resultado, se elaborados à luz do custo histórico puro e na ausência de inflação, são a distribuição lógica e racional ao longo do tempo do Fluxo de Caixa da empresa".

E, ainda prosseguem:

De outra forma, poder-se-ia afirmar: todos os elementos do Balanço e da Demonstração de Resultado, sem exceção, passam, em algum momento, pelo caixa. [...] o modelo do FASB, ao não atentar para os aspectos financeiros que envolvem as transações a prazo, distorce o poder informativo da DFC.

Pela DFC podem-se obter informações acerca das alterações históricas de caixa e equivalentes de caixa de uma entidade por meio dos fluxos classificados por atividades operacionais, de investimento e de financiamento.

Definiu pelos itens 11 e 12 do Pronunciamento Técnico $n^{\circ} 03$, que a Demonstração dos Fluxos de Caixa deve apresentar:

a) os fluxos de caixa de período classificados por atividades operacionais, de investimento e de financiamento;

b) os fluxos de caixa decorrentes das atividades operacionais, de investimento e de financiamento da forma que seja mais apropriada 
a seus negócios. A classificação por atividade proporciona informações que permitem aos usuários avaliar o impacto de tais atividades sobre a posição financeira da entidade e o montante de seu caixa e equivalentes de caixa.

O Pronunciamento Técnico - $\mathrm{CPC} \mathrm{n}^{\circ} 03$-, foi bem recebido pelos órgãos reguladores e teve o seu conteúdo normativo integralmente aprovado, por meio dos respectivos instrumentos de regulação, como segue:

CVM - Deliberação CVM 547/08;

CFC - NBC T 3.8 - Resolução CFC no 1.125/08;

CMN - Resolução no 3.604/08 (Banco Central do Brasil);

SUSEP - Circular SUSEP no 379/08 (anexo I);

ANEEL - Despacho no 4.796/08 e Ofício-Circular $n^{\circ}$ 2.775/08-SFF/ANEEL;

ANTT - Comunicado SUREG n 1/09.

A esse respeito, o site da CVM (2008), informa que foram feitos acréscimos que abarcam aspectos específicos e exclusivos para ajustar os seus termos à realidade brasileira, e que não afetaram o núcleo do que preceitua a Norma Internacional IAS 7 -, que deu origem ao CPC 03/08, como: foi acrescentada a expressão "e juros sobre o capital próprio" nos itens que fazem referência a dividendos; incluída a reconciliação entre o lucro líquido e o fluxo de caixa líquido das atividades operacionais independentemente de a entidade usar o método direto ou indireto, dos diferimentos, provisões e de outros ajustes ao lucro líquido;

O documento incluiu a determinação de que: "as demonstrações contábeis não devem divulgar qualquer valor de fluxo de caixa por ação." e "nem o fluxo de caixa líquido nem quaisquer de seus componentes são substitutos do lucro líquido como indicador de desempenho da entidade, como a divulgação de um fluxo de caixa por ação poderia sugerir".

Determinou, também, que a DFC deve demonstrar as mudanças ocorridas no período nos recebíveis, nos estoques, nos pagamentos vinculados às atividades operacionais e, se o método indireto for utilizado, os montantes de juros (líquidos dos valores capitalizados) e os valores do imposto de renda e da contribuição so- 
cial, devem ser separados dos valores retidos na fonte de terceiros e apenas recolhidos pela entidade;

\section{Estrutura financeira da entidade segundo a DFC}

A Demonstração do Fluxo de Caixa pode mostrar-se bastante útil (item 05 e 06 do Pronunciamento Técnico CPC 03/08), se as suas informações forem analisadas e avaliadas em conjunto com as demais demonstrações contábeis, o que pode permitir ao usuário o conhecimento da estrutura financeira da entidade e de suas variações no tempo, bem como, a verificação da capacidade de adaptação da entidade a situações nas quais prevalece na decisão, a opção por preços, prazos ou circunstâncias que podem significar oportunidade de bons negócios.

Sobre a DFC, Santos e Schmidt (2009, p. 360) acrescentam que:

Secundariamente ela objetiva fornecer a compreensão das atividades de investimento e financiamento de uma entidade. Dessa forma, a demonstração do fluxo de caixa auxilia os investidores e os credores a avaliar:

a capacidade de geração de fluxos futuros de caixa positivos; a capacidade de cumprir suas obrigações e pagar dividendos; as razões para a diferença entre resultado do exercício e os recebimentos e pagamentos de caixa;

os aspectos caixa e não caixa das transações de investimento e financiamento da entidade

Já, Marques e Braga (2001) entendem que:

Em sentido amplo, a demonstração de fluxos de caixa (DFC) tem como finalidade apresentar informações sobre os fluxos das transações e eventos que afetaram o caixa da empresa ao longo de um determinado período, de uma forma organizada e estruturada por atividades, permitindo uma melhor compreensão da articulação entre as diversas demonstrações financeiras. 


\section{Definições de termos}

O Pronunciamento do CPC 03/08, definiu o significado das operações e dos termos, normalmente utilizados na elaboração da Demonstração do Fluxo de Caixa:

CAIXA - compreende numerário em espécie e depósitos bancários disponíveis.

EQUIVALENTES DE CAIXA - referem-se a aplicações financeiras de curto prazo, de alta liquidez, que são prontamente conversíveis em um montante conhecido de caixa e que estão sujeitas a um insignificante risco de mudança de valor. Os equivalentes de caixa são mantidos com a finalidade de atender a compromissos de caixa de curto prazo e não para investimento ou outros fins.

FLUXOS DE CAIXA - trata das entradas e saídas de caixa e equivalentes de caixa. Os fluxos de caixa excluem movimentos entre itens que constituem caixa ou equivalentes de caixa porque esses componentes são parte da gestão financeira da entidade e não parte de suas atividades operacionais, de investimentos ou de financiamento. A gestão do caixa inclui o investimento do excesso de caixa em equivalentes de caixa.

ATIVIDADES OPERACIONAIS - são as principais atividades geradoras de receita da entidade e outras atividades diferentes das de investimento e de financiamento. ATIVIDADES DE INVESTIMENTO - são as atividades referentes à aquisição e à venda de ativos de longo prazo e de outros investimentos não incluídos nos equivalentes de caixa.

ATIVIDADES DE FINANCIAMENTO - são as atividades que resultam em mudanças no tamanho e na composição do capital próprio e no endividamento da entidade, não classificadas como atividade operacional. Empréstimos bancários são geralmente considerados como atividades de financiamento. Assim, deverão ser considerados os saldos bancários a descoberto, decorrentes de empréstimos obtidos por meio de instrumentos como cheques especiais ou contas correntes garantidas. A parcela não utilizada do limite dessas linhas de crédito não deverá compor os equivalentes de caixa. 
Além disso, em relação aos componentes de caixa e equivalentes de caixa, a entidade deve:

a) divulgar os componentes de caixa e equivalentes de caixa e deve apresentar uma conciliação dos valores em sua demonstração dos fluxos de caixa com os respectivos itens divulgados no balanço patrimonial. (Item 49 do Pronunciamento Técnico CPC 03/08);

b) divulgar a política que adota na determinação da composição do caixa e equivalentes de caixa. (Item 50 do Pronunciamento Técnico CPC 03/08);

c) apresentar os efeitos de qualquer mudança para determinar os componentes de caixa e equivalentes de caixa, de acordo com base no Pronunciamento Técnico CPC 23 - Políticas Contábeis, Mudança de Estimativa e Retificação de Erro (Item 51 do Pronunciamento Técnico CPC 03/08).

\section{Ajustes no Pronunciamento Técnico 03/08 pelos órgãos reguladores}

A Deliberação CVM nº 624, de 28 de janeiro de 2010 acatou os termos da Revisão CPC no 1 de Pronunciamentos Técnicos e Orientação Técnica e, ao referir-se ao item 8 do Pronunciamento Técnico CPC 03, sugere que a qualificação como equivalente de caixa deva ter vencimento de curto prazo, por exemplo, três meses ou menos, a contar da data da contratação.

A CVM definiu que os investimentos em ações de outras entidades devem ser excluídos dos equivalentes de caixa a menos que eles sejam, em essência, um equivalente de caixa, como, por exemplo, nos casos de ações preferenciais resgatáveis que tenham prazo definido de resgate e cujo prazo atenda a definição de curto prazo.

A Deliberação CVM nº 624/10, alterou também, o item 9 do Pronunciamento Técnico CPC 03 (COMITÊ DE PRONUNCIAMENTOS CONTÁBEIS, 2008): 
Empréstimos bancários são geralmente considerados como atividades de financiamento. Entretanto, em determinadas circunstâncias, saldos bancários a descoberto, decorrentes de empréstimos obtidos por meio de instrumentos como cheques especiais ou contas-correntes garantidas são liquidados automaticamente de forma a integrarem a gestão das disponibilidades da entidade. Uma característica de tais contas correntes é que freqüentemente os saldos flutuam de devedor para credor. Nessas circunstâncias, esses saldos bancários a descoberto devem ser incluídos como componente de caixa e equivalentes de caixa. A parcela não utilizada do limite dessas linhas de crédito não deve compor os equivalentes de caixa. (NR)

O Conselho Monetário Nacional aprovou e, o Banco Central regulamentou no Art. $3^{\circ}$ da Resolução BCB n 3.604, de 29 de agosto de 2008, que:

para ser considerado equivalente de caixa, um investimento deve ter, na data de aquisição, prazo de vencimento igual ou inferior a noventa dias;

investimentos em instrumentos de capital não são considerados equivalentes de caixa, a menos que, em essência, preencham os requisitos previstos no CPC 03 e nesta resolução.

Já a Circular SUSEP n 379, de 19 de dezembro de 2008 - Anexo I - 30 Fluxo de Caixa, no âmbito de sua jurisdição determinou o uso do método direto e dispensou as sociedades do mercado supervisionado pela SUSEP de apresentar a reconciliação entre o lucro líquido e o fluxo de caixa líquido das atividades operacionais e regulamentou que:

30.1.1 Para ser considerado equivalente caixa, um investimento deve ter, na data de aquisição, prazo de vencimento igual ou inferior a noventa dias;

30.1.2 Investimentos em instrumentos de capital não são considerados equivalentes de caixa, a menos que, em essência, preencham os requisitos previstos no CPC 03 (BRASIL, 2008).

Já a ANEEL, por meio do Ofício-Circular no 2.775/08-SFF/ANEEL recomendou a adoção pelo método direto para a elaboração da DFC do exercício de 2008, e sua obrigatoriedade para o exercício de 2009. 


\section{As formas de apresentação da DFC}

A Lei 6.404/76, em seu Art. 188, Incisos e alíneas determina que a Demonstração dos Fluxos de Caixa deva indicar, no mínimo, as alterações ocorridas, durante o exercício, no saldo de caixa e equivalentes de caixa, segregados por atividades:

a) das operações;

b) dos financiamentos; e

c) dos investimentos.

O Comitê de Pronunciamentos Contábeis (CPC), aprovou o Pronunciamento Técnico ${ }^{\circ} 03$-, determinou que a entidade deve divulgar os fluxos de caixa das atividades operacionais, de investimento e de financiamento usando o método direto ou o indireto.

\section{Demonstração dos Fluxos de Caixa pelo Método Direto}

Fluxos de caixa das atividades operacionais

Recebimentos de clientes

Pagamentos a fornecedores e empregados

Caixa gerado pelas operações Juros pagos

Imposto de renda e contribuição social pagos

Imposto de renda na fonte sobre dividendos recebidos

Caixa líquido proveniente das atividades operacionais

Fluxos de caixa das atividades de investimento

Aquisição da controlada X líquido do caixa incluído na aquisição (Nota A)

Compra de ativo imobilizado (Nota B)

Recebido pela venda de equipamento

Juros recebidos

Dividendos recebidos

Caixa líquido usado nas atividades de investimento

Fluxos de caixa das atividades de financiamento

Recebido pela emissão de ações

Recebido por empréstimo a logo prazo

Pagamento de passivo por arrendamento

Dividendos pagos*

Caixa líquido usado nas atividades de financiamento

Aumento líquido de caixa e equivalentes de caixa

Caixa e equivalentes de caixa no início do período (Nota $\mathrm{C}$ )

Caixa e equivalentes de caixa ao fim do período (Nota $\mathrm{C}$ )

A seguir, como ilustração, um modelo de Fluxo de Caixa pelos Métodos direto ou o indireto

$\left.{ }^{*}\right)$ - Esse valor também pode ser apresentado no fluxo de caixa das atividades operacionais Fonte: Pronunciamento Técnico CPC 03/08, de 13/06/2008 
Demonstração dos Fluxos de Caixa pelo Método Indireto

Fluxos de caixa das atividades operacionais

Lucro líquido antes do imposto de renda e contribuição social

Ajustes por:

Depreciação

Perda cambial

Renda de investimentos

Despesas de juros

Aumento nas contas a receber de clientes e outros

Diminuição nos estoques

Diminuição nas contas a pagar - fornecedores

Caixa proveniente das operações

Juros pagos

Imposto de renda e contribuição social pagos

Imposto de renda na fonte sobre dividendos recebidos

Caixa líquido proveniente das atividades operacionais

Fluxos de caixa das atividades de investimento

Aquisição da controlada X menos caixa líquido incluído na aquisição (Nota A)

Compra de ativo imobilizado (Nota B)

Recebimento pela venda de equipamento

Juros recebidos

Dividendos recebidos

Caixa líquido usado nas atividades de investimento

Fluxos de caixa das atividades de financiamento

Recebimento pela emissão de ações

Recebimento por empréstimos a longo prazo

Pagamento de obrigação por arrendamento

Dividendos pagos*

Caixa líquido usado nas atividades de financiamento

Aumento líquido de caixa e equivalente de caixa

Caixa e equivalente de caixa no início do período

Caixa e equivalente de caixa no fim do período

Fonte: Pronunciamento Técnico CPC 03/08, de 13/06/2008

No Método Direto devem ser divulgadas as principais classes de recebimentos brutos e pagamentos brutos (item 20, do Pronunciamento Técnico $n^{\circ} 03$ ), obtidos nos registros contábeis da entidade; ou, alternativamente por meio do ajuste de vendas, custos das vendas e outros itens da demonstração do resultado referentes a:

mudanças ocorridas no período nos estoques e nas contas operacionais a receber e a pagar;

outros itens que não envolvem caixa; e 
outros itens cujos efeitos no caixa sejam fluxos de caixa decorrentes das atividades de financiamento e de investimento. (item 20 do Pronunciamento Técnico ${ }^{\circ}$ 03)

No Método Indireto o lucro líquido ou prejuízo é ajustado pelos efeitos das transações que não envolvem caixa:

de quaisquer diferimentos ou outras apropriações por competência sobre recebimentos ou pagamentos operacionais passados ou futuros; e

de itens de receita ou despesa associados com fluxos de caixa das atividades de investimento ou de financiamento. (item 20 do Pronunciamento Técnico ${ }^{\circ}$ 03).

Segundo o item 22, do Pronunciamento Técnico $\mathrm{n}^{\circ}$ 03, ajustam-se o lucro líquido ou prejuízo quanto aos efeitos de:

mudanças ocorridas no período nos estoques e nas contas operacionais a receber e a pagar;

itens que não afetam o caixa, tais como depreciação, provisões, impostos diferidos, variações cambiais não realizadas, resultado de equivalência patrimonial em investimentos e participação de minoritários, quando aplicável; e

todos os outros itens cujos efeitos sobre o caixa sejam fluxos de caixa decorrentes das atividades de investimento ou de financiamento.

\section{Aspectos que devem ser considerados na elaboração da DFC}

\subsection{Nas atividades operacionais}

Sobre as atividades operacionais o pronunciamento (item14 do Pronunciamento Técnico ${ }^{\circ}$ 03) destaca que o montante dos fluxos de caixa decorrentes dessas atividades é um indicador chave da extensão na qual as operações da entidade têm gerado suficientes fluxos de caixa para:

amortizar empréstimos;

manter a capacidade operacional da entidade;

pagar dividendos e juros sobre o capital próprio e

fazer novos investimentos sem recorrer a fontes externas de financiamento. 
As informações sobre os componentes específicos dos fluxos de caixa operacionais históricos são úteis, em conjunto com outras informações, na projeção de futuros fluxos de caixa operacionais.

Esses fluxos são basicamente derivados das principais atividades geradoras de receita da entidade e geralmente resultam das transações e de outros eventos que entram na apuração do lucro líquido ou prejuízo. (item 15, do Pronunciamento Técnico $\left.n^{\circ} 03\right)$.

São exemplos de fluxos de caixa que decorrem das atividades operacionais:

a) recebimentos de caixa pela venda de mercadorias e pela prestação de serviços;

b) recebimentos de caixa decorrentes de royalties, honorários, comissões e outras receitas;

c) recebimentos e pagamentos de caixa por seguradora de prêmios e sinistros, anuidades e outros benefícios da apólice;

d) recebimentos e pagamentos de caixa de contratos mantidos para negociação imediata ou disponíveis para venda futura;

e) pagamentos de caixa a fornecedores de mercadorias e serviços;

f) pagamentos de caixa a empregados ou por conta de empregados;

g) pagamentos ou restituição de caixa de impostos sobre a renda, a menos que possam ser especificamente identificados com as atividades de financiamento ou de investimento;

Devem, ainda, ser consideradas como atividades operacionais: (item 15 e 16 do Pronunciamento Técnico $\mathrm{n}^{\circ} 03$ )

a) os pagamentos para a produção ou aquisição de ativos destinados a aluguel para terceiros e, subsequentes vendas;

b) os recebimentos de aluguéis e das subsequentes vendas de tais ativos;

c) a compra e venda de títulos e empréstimos que a entidade dispõe para fins de intermediação que sejam semelhantes a estoques adquiridos especificamente para revenda; e 
d) as antecipações de caixa e os empréstimos feitos por instituições financeiras.

Recomenda-se, também, no item 17 do Pronunciamento Técnico $n^{\circ} 03$ que deve ser feita a conciliação entre o lucro líquido e o fluxo de caixa líquido das atividades operacionais, essencial para que os usuários tenham elementos para avaliar os efeitos líquidos das atividades operacionais e de outros eventos que afetam o lucro líquido e os fluxos operacionais de caixa em diferentes períodos.

\subsection{Nas atividades de investimento}

Os fluxos de caixa atividades de investimentos, regulados no item 18, do Pronunciamento Técnico $n^{\circ} 03$, representam a extensão em que os dispêndios de recursos são feitos pela entidade com a finalidade de gerar resultados e fluxos futuros, daí ser relevante sua apresentação em separado.

São exemplos de fluxos de caixa que decorrem das atividades de investimentos:

a) pagamentos de caixa para aquisição de ativo imobilizado, intangível e outros ativos de longo prazo, os desembolsos com os custos de desenvolvimento ativados e ativos imobilizados de construção própria;

b) pagamentos para aquisição de ações ou instrumentos de dívida de outras entidades e participações societárias em joint ventures, exceto a títulos mantidos para negociação imediata ou venda futura;

c) pagamentos de caixa por contratos futuros, a termo, de opção e swap, exceto se os contratos forem mantidos para negociação imediata ou venda futura, ou os pagamentos forem classificados como atividades de financiamento;

d) adiantamentos de caixa e empréstimos feitos a terceiros, exceto aqueles feitos por instituição financeira;

e) recebimentos de caixa resultantes da venda de ativo imobilizado, intangível e outros ativos de longo prazo; 
f) recebimentos de caixa provenientes da venda de ações ou instrumentos de dívida de outras entidades e participações societárias em joint ventures, exceto aqueles considerados como equivalentes de caixa e os mantidos para negociação;

g) recebimentos de caixa por liquidação de adiantamentos ou amortização de empréstimos concedidos a terceiros, exceto adiantamentos e empréstimos feitos por instituição financeira; e

h) recebimentos de caixa por contratos futuros, a termo, de opção e swap, exceto aqueles mantidos para negociação imediata ou venda futura, e os recebimentos classificados como atividades de financiamento.

Quando um contrato for contabilizado como proteção (hedge) de uma posição identificável, os fluxos de caixa do contrato devem ser classificados do mesmo modo.

\subsection{Nas atividades de financiamento}

A divulgação em separado dos fluxos de caixa decorrentes das atividades de financiamento é importante a sua utilidade na previsão das exigências sobre futuros fluxos de caixa pelos fornecedores de capital à entidade (item 19 do Pronunciamento Técnico $n^{\circ} 03$ ).

Constituem-se em exemplos de fluxos de caixa decorrentes das atividades de financiamento:

a) caixa recebido pela emissão de ações ou outros instrumentos patrimoniais;

b) caixa recebido proveniente da emissão de debêntures, empréstimos, títulos e valores, hipotecas e outros empréstimos de curto e longo prazos;

c) pagamentos de caixa a investidores para adquirir ou resgatar ações da entidade; 
d) pagamentos de caixa por arrendatário, para redução do passivo relativo a arrendamento mercantil financeiro; $\mathrm{e}$

e) amortização de empréstimos e financiamentos, incluindo debêntures emitidas, hipotecas, mútuos e outros empréstimos de curto e longo prazos.

\section{Outra formas de divulgação dos fluxos de caixa}

\subsection{Fluxos de caixa em base líquida}

Apesar de os métodos diretos e indiretos divulgarem as informações brutas, as atividades operacionais, de investimento e de financiamento podem, também, ser apresentados numa base líquida nas situações em que houver:

a) recebimentos e pagamentos de caixa em favor ou em nome de clientes, quando os fluxos de caixa refletirem mais as atividades dos clientes do que as da própria entidade, como segue:

movimentação (depósitos e saques) em contas de depósitos à vista em um banco;

fundos mantidos para clientes por uma companhia de investimento; e

aluguéis cobrados em nome de terceiros e pagos inteiramente aos proprietários dos imóveis.

b) recebimentos e pagamentos de caixa referentes a itens cuja rotação seja rápida, os valores sejam significativos e os vencimentos sejam de curto prazo:

pagamentos e recebimentos relativos aos cartões de crédito de clientes;

compra e venda de investimentos; e

outros empréstimos tomados em curto prazo, como, por exemplo, os que têm vencimento em três meses ou menos contados a partir da respectiva contratação (item 24, 25 e 26 do Pronunciamento Técnico $\mathrm{n}^{\circ} 03$ ).

$\mathrm{Na}$ Instituição financeira podem ser apresentados em base líquida: recebimentos e pagamentos de caixa pelo aceite e resgate de depósitos a prazo fixo; 
colocação de depósitos ou sua retirada de outras; adiantamentos e empréstimos de caixa feitos a clientes, e a amortização desses adiantamentos e empréstimos (item 27 do Pronunciamento Técnico $n^{\circ} 03$ ).

\subsection{Fluxos de caixa em moeda estrangeira}

Os fluxos de caixa decorrentes de transações em moeda estrangeira (itens 28 a 31 do Pronunciamento Técnico $n^{\circ}$ 03) determinam a observância às regras contidas no Pronunciamento 02 - Efeitos das mudanças nas taxas de câmbio e conversão de demonstrações contábeis, editado em correlação com a IAS 21, a seguir:

a) os fluxos devem ser registrados na moeda funcional da entidade, convertendo-se o montante em moeda estrangeira à taxa cambial na data de cada fluxo de caixa;

b) admite o uso da taxa média ponderada de câmbio para um período, se o resultado não for substancialmente diferente daquele que seria obtido com o uso de taxas de câmbio das datas de cada fluxo de caixa;

c) os fluxos de caixa de controlada no exterior devem ser convertidos para a moeda funcional da controladora, utilizando-se a taxa cambial na data de cada fluxo de caixa;

d) não admite o uso da taxa de câmbio da data do balanço patrimonial para conversão da demonstração dos fluxos de caixa de controladas ou coligadas no exterior; $\mathrm{e}$

e) não considera fluxos de caixa os ganhos e perdas não realizados resultantes de mudanças nas taxas de câmbio de moedas estrangeiras, no entanto, os efeitos das mudanças nas taxas cambiais sobre o caixa e equivalentes de caixa, mantidos ou devidos em moeda estrangeira, devem ser apresentados na demonstração dos fluxos de caixa, a fim de reconciliar os valores do inicio e final do período. Complementarmente, determina que o valor encontrado seja apresentado separadamente dos fluxos de caixa das atividades operacionais, de investimento e de financiamento. 


\section{Divulgação de informações adicionais}

O Pronunciamento Técnico $n^{\circ} 03 / 08$, não admite a divulgação do valor dos fluxos de caixa por ação e alerta sobre o fato de o fluxo de caixa líquido ou quaisquer de seus componentes substituírem o lucro líquido como indicador de desempenho da entidade;

Cria a possibilidade de divulgação de informações adicionais ou complementares para melhor entendimento dos usuários, podendo incluir:

em nota explicativa, acompanhada de um comentário da administração, os saldos de caixa e equivalentes de caixa que não estejam disponíveis para uso pelo grupo, por exemplo, em poder de controlada que opere em país com controles cambiais ou restrições legais que impeçam o uso geral dos saldos pela controladora ou outras controladas;

o valor de linhas de crédito obtidas, mas não utilizadas, que podem estar disponíveis para futuras atividades operacionais e para satisfazer compromissos de capital, indicando se há restrições para o uso;

o valor dos fluxos de caixa de cada uma das atividades operacionais, de investimento e de financiamento, referentes aos investimentos em entidades de controle conjunto, contabilizado mediante o uso da consolidação proporcional;

o valor dos fluxos de caixa que representam aumentos na capacidade operacional, separadamente dos fluxos de caixa que são necessários para apenas manter a capacidade operacional;

o valor dos fluxos de caixa decorrentes das atividades operacionais, de investimento e de financiamento de cada segmento industrial, comercial ou de serviços e geográfico; os montantes totais, separadamente, dos juros e dividendos e juros sobre o capital próprio, pagos e recebidos, bem como o montante total do imposto de renda e da contribuição social sobre o lucro líquido pagos, neste caso destacando os retidos na fonte de terceiros e apenas recolhidos pela entidade; e

a divulgação dos fluxos de caixa por segmento (itens 52 a 57 do Pronunciamento Técnico $\mathrm{n}^{\circ} 03$ ). 


\section{Apresentação e discussão dos aspectos relevantes do estudo}

\subsection{As controvérsias do conteúdo normativo do Pronunciamento Técnico 03/08}

As alterações promovidas na Lei 6.404/76 - Lei das Sociedades por ações, pelas Leis 11.638/07 e 11.944/09, precipitaram a ação do Comitê de Pronunciamentos Contábeis em relação à promoção de Audiências Públicas para a discussão que subsidiasse a edição dos Pronunciamentos Técnicos, que permitissem adequar e convergir às normas contábeis nacionais às estrangeiras.

A tradução do IAS 7, Demonstração dos Fluxos de Caixa, cujo conteúdo normativo se baseou no Financial Accounting Standard - FAS 95: Statement of Cash Flows (Demonstração de Fluxo de Caixa), transformou-se em minuta do Pronunciamento Técnico CPC 03/08 - Demonstração de Fluxos de Caixa que foi submetido à discussão em audiências públicas, pelo Comitê de Pronunciamentos Contábeis (CPC), em 2008.

Convém destacar que o Relatório da Audiência Pública 01/08, de 13 de março de 2008, acolheu e adotou as regras do IAS 7, com alguns poucos ajustes, que no todo, não alteraram sua essência:

A fidelidade a este texto só não foi completa em razão de pouquíssimos ajustes, que foram feitos com o objetivo de proporcionar maior clareza e objetividade ao usuário da demonstração dos fluxos de caixa, sem nunca excluir ou deixar de atender às disposições contidas no pronunciamento do IASB sobre o tema.

E complementa, afirmando que:

Foram feitos também alguns ajustes imprescindíveis ao caso brasileiro: onde a norma internacional se refere a dividendos, no pronunciamento local escreveu-se "dividendos ou juros sobre o capital próprio". O mesmo se fez em relação ao imposto de renda ("imposto de renda e contribuição social sobre o lucro líquido”). (RELATÓRIO DA AUDIÊNCIA PÚBLICA, 2008). 
A edição do Pronunciamento Técnico CPC nº 03/08, trouxe para os usuários várias expectativas, em relação à objetividade do conteúdo da norma que poderia esclarecer dúvidas existentes em função da legislação já editada e, em vigor; em relação às vantagens ou desvantagens da substituição da DOAR pela DFC face à sua utilização e, quanto à qualidade e transparência das informações geradas pela DFC.

Santos e Freitas (2000), ao discutirem a substituição e as diferenças entre a DOAR e a DFC, assim se manifestaram nos Anais do XVI Congresso Brasileiro de Contabilidade:

Evidentemente que no que tange ao aspecto informacional é indiscutível a predominância da DOAR sobre a DFC, pelo menos para os que conhecem com profundidade os conceitos contábeis contidos em ambas as demonstrações, e o papel fundamental que as informações nelas evidenciadas tem para a gestão empresarial.

Contudo, o objetivo da contabilidade é produzir informação útil para uma gama enorme de usuários que na grande maioria das vezes não possuem o nível desejado de conhecimento sobre contabilidade que os possibilite perceber que preterir a DOAR em detrimento da DFC talvez seja um grande equivoco.

A DOAR possui alguns pontos comuns com a DFC, porém é muito mais rica em informações. A DOAR é mais analítica, mostra a posição financeira, suas tendências futuras. A DFC propicia informações concretas, se houve ou haverá dinheiro, quanto se deve tomar de empréstimos. A DFC é um instrumento com característica de curto prazo, voltada para o usuário interno, já ao usuário externo deixa a desejar. Já a DOAR tem característica de médios e longos prazos, permite a seus usuários perceber a política e a tendência das empresas no futuro.

Enquanto a DFC compreende o movimento de fluxo de dinheiro, a DOAR volta-se para a movimentação havida nos recursos e aplicações permanentes, ou de longo prazo e, como conseqüência disto, o impacto na situação financeira, espelhada pela variação do CCL.

Também nos Anais do XVI Congresso Brasileiro de Contabilidade, Giasson et al. (2000) assim se manifestaram: 
Tanto a DOAR como a DFC têm alguns pontos que são passivos de criticas em sua eficácia como instrumento de informações. A DOAR apresenta o conceito abstrato de Capital Circulante Líquido que pode aparentemente apresentar uma situação confortável para a empresa, mas devido os prazos de recebimentos e estocagem serem elevados, a empresa pode ficar com dificuldades financeiras a curto prazo. Já a DFC pode facilmente ser manipulada, a empresa pode conduzir seus fluxos de caixa, atrasando os pagamentos a fornecedores, apresentando assim uma situação financeira irreal, além de seu conteúdo informacional ser inferior ao da DOAR.

Considerando as características da DOAR e da DFC pelo método direto, podemos concluir que uma demonstração complementa a outra, assim as informações que a DOAR não evidencia dentro do próprio circulante (CCL), seriam apresentadas pela DFC (método direto). Portanto, a maioria das criticas feitas a essas demonstrações seriam eliminadas, se ambas fossem apresentadas em conjunto, aumentando assim a qualidade das informações contábeis.

Outro aspecto refere-se às dúvidas em relação à escolha entre o Método Direto e Indireto para a elaboração da Demonstração do Fluxo de Caixa já que o Comitê de Pronunciamentos Contábeis $n^{\circ}$ 03/08, deixou a decisão a critério das entidades.

Porém, a Circular SUSEP nº 379/08, Anexo I, no item 30, eliminou, no âmbito de sua jurisdição, essa lacuna, ao determinar o uso do Método Direto na elaboração da Demonstração do Fluxo de Caixa.

A ANEEL, por meio do Ofício-Circular no 2.775/08-SFF/ANEEL recomendou a adoção pelo método direto para a elaboração da DFC do exercício de 2008, e sua obrigatoriedade para o exercício de 2009.

O Conselho Monetário Nacional e a Superintendência de Seguros Privados utilizaram como solução a Resolução CMN n 3.604/08 (Banco Central do Brasil) e a Circular SUSEP no 379/08, Anexo I, item 30, cujo teor regula contrariamente ao CPC03/08, e dispensa: 
A necessidade de conciliação do resultado, com o fluxo de caixa operacional se a entidade optar pelo método direto; determina que um investimento para ser considerado equivalente de caixa, deve ter prazo de vencimento de até 90 dias e, que os investimentos em instrumentos de capital não podem ser considerados equivalentes de caixa.

Em relação ao conceito e à classificação de equivalente de caixa, a Revisão CPC n ${ }^{\circ} .1$ de Pronunciamentos Técnicos e Orientação Técnica passou a adotar a determinação já assumida pela Resolução CMN n 3.604/08 e a Circular SUSEP nº 379/08, Anexo I, item 30.

Essas alterações foram homologadas e adotadas pela CVM, por meio da Deliberação CVM 624/10 de 28 de Janeiro de 2010 e pelo CFC, por meio da Res CFC 1273/10 de 22 de janeiro de 2010.

Outra polêmica reside na afirmativa de que o fluxo de caixa independe dos critérios contábeis, além de falacioso é desprovido de fundamentação teórica que o justifique e ampare. Qualquer relatório contábil, em especial, as demonstrações contábeis, consubstancia-se no registro, acumulação e predição dos atos e fatos econômicos inerentes às atividades da entidade. Ao contrário da afirmativa do pressuposto, qualquer reconhecimento de receitas, despesas e custos deve submeter-se, obrigatoriamente, aos Princípios Contábeis, às Normas da Profissão e aos preceitos emanados da Legislação Societária.

Reafirmam essa assertiva, a Ernst e Young e Fipecafi (2010, p. 76-77), quando assim se manifestaram:

No fundo, toda a atividade empresarial está à busca de fluxos de caixa de entrada que, ao longo do tempo, superem os de saída e provoquem a figura do lucro que, em última instância, é acréscimo de caixa para os investidores. [...] O vínculo, portanto, entre a contabilidade e o caixa sempre foi umbilical. Isso, por si só, já justifica a "volta" da contabilidade por competência ao fluxo de caixa para que, em conjunto, ambos (balanço e resultado de um lado, e fluxo de caixa do outro), dêem uma visão completa do que ocorre com a empresa. 


\subsection{As ilustrações do pronunciamento}

O Pronunciamento Técnico $\mathrm{n}^{\circ} 03$, teve a iniciativa de, no Apêndice, apresentar ilustração da elaboração da Demonstração do Fluxo de Caixa - DFC, com exemplo simulado, na tentativa de facilitar a compreensão do conteúdo normativo (ver simulação anexa).

Porém, essa iniciativa ficou comprometida, pois a simulação apresentada utilizou como fonte, dados já apresentados e publicados pelo IBRACON (1998, p. 98-105), que foram adaptados no $\mathrm{CPC} \mathrm{n}^{\circ} 03 / 08$, porém sem observar que reflexos poderiam gerar nos resultados, face à legislação vigente e os princípios contábeis aplicáveis.

Dessa ilustração convêm anotar que a melhor opção para apresentação da simulação deveria ser no "Anexo", por se tratar de informações "produzidas por terceiros", com informação ao usuário e que se trata de exemplos adaptados e não no "Apêndice".

Foram mantidos os valores originariamente publicados e, em alguns itens, sem considerar que a situação atual possa ser diferente, como segue:

a) foi acrescido ao imposto de renda a pagar, a contribuição social para o lucro líquido a pagar no inicio e no final do período e mantidos os valores de 1000 e 400, respectivamente (não há como identificar e associar a que se referem os valores);

b) no mesmo item apresenta-se uma provisão no valor de 200, sem no entanto, especificar se é para o imposto de renda ou contribuição social para o lucro líquido; (não há como identificar a que se referem os valores e como foram determinados);

c) foi incluída a informação do recebimento de juros de 200, (não há referência nem correspondência sobre a sua origem); o mesmo item traz o recebimento de dividendos - líquidos de imposto na fonte de 100 - de 200 (a redação utilizada está tão confusa que não permite perceber com clareza se o valor bruto é 200 e o imposto 100, ou vice-versa); e 
d) foi incluído o pagamento no período de 90 de arrendamento mercantil (não há informações complementares sobre essa operação).

\section{Conclusão}

As alterações da Lei 6.404/76 - Lei das Sociedades por Ações, pelas Leis 11.638/07 e 11.944/09, precipitaram a ação do Comitê de Pronunciamentos Contábeis em relação à promoção de Audiências Públicas para discussão de tremas que subsidiassem a edição dos Pronunciamentos Técnicos, e que permitissem adequar e convergir as normas contábeis nacionais às estrangeiras.

Essa precipitação do Comitê de Pronunciamentos Contábeis, resulta da descrença no Parlamento brasileiro, que historicamente dispõe de pouco ânimo para deliberar sobre assuntos que não lhes interessam diretamente, o que fez com que o Projeto de lei no. 3.741, de 2000, adormecesse por 07 anos nas gavetas do Congresso Nacional, cuja promulgação e sanção da Lei n 11.638/2007, em 28/12/2007 e da Lei 11. 941, de 27/05/2009. Esta última editada para corrigir imperfeições apresentadas nas mudanças.

Especificamente em relação à obrigatoriedade da publicação da DFC, a Lei 11.638/07 trouxe para os profissionais da área contábil, além da natural curiosidade, dúvidas em relação aos procedimentos e critérios para sua elaboração e quanto à sua abrangência.

A edição do Pronunciamento Técnico CPC nº 03/08, objetivou esclarecer os aspectos que envolvem a elaboração da DFC porém, ainda pairam dúvidas em relação à objetividade do conteúdo e quanto à convergência das normas contábeis nacionais às estrangeiras; sobre as vantagens ou desvantagens da substituição da DOAR pela DFC e, referentes à qualidade e transparência, das informações que passariam a ser geradas pela DFC, para os usuários. 
Esses aspectos suscitam discussões, sobre as diferenças da DOAR e a DFC, bem como, sobre as vantagens ou desvantagens. Das opiniões dos estudiosos, pode-se observar que:

a) a DOAR apesar dos pontos comuns com a DFC, - é muito mais rica em informações, tem característica de médio e longo prazos, além de ser mais analítica, pois ao mostrar a posição financeira apresenta suas tendências futuras;

b) no aspecto informacional é indiscutível a predominância da DOAR sobre a DFC, porém ambas apresentam pontos que são passiveis de criticas em relação à sua eficácia como instrumento de informações; e

c) a DFC é um instrumento com característica de curto prazo, voltada para o usuário interno, já em relação ao usuário externo deixa a desejar.

Em relação às dúvidas alguns aspectos relevantes, podem ser destacados:

a escolha entre o Método Direto e Indireto para a elaboração da Demonstração do Fluxo de Caixa, depende de avaliação técnica de cada entidade, pois o Pronunciamentos Técnico $\mathrm{n}^{\circ}$ 03/08 deixou ao livre arbítrio destas. Essa falta de definição está sendo suprida, pelos órgãos reguladores, em função das necessidades e dificuldades que cada um depara como a iniciativa da SUSEP por meio da Circular SUSEP $\mathrm{n}^{\circ}$ 379/08, Anexo I, no item 30, e da ANEEL, mediante o Ofício-Circular n 2.775/08-SFF/ANEEL.

o conceito e a classificação de equivalente de caixa e a conciliação do resultado, com o fluxo de caixa operacional, não foram aceitos pelo Conselho Monetário Nacional que editou Resolução CMN no 3.604/08 (Banco Central do Brasil) e, pela Superintendência de Seguros Privados, que aprovou a Circular SUSEP n ${ }^{\circ} 379 / 08$, Anexo I, item 30 , cujos teores regulam contrariamente ao conteúdo do CPC03/08 sobre o assunto. 
Essas decisões fizeram com que o CPC após promover audiências públicas sobre o assunto, em 2009, editasse em Janeiro de 2.010 a Revisão CPC nº 1 de Pronunciamentos Técnicos e Orientação Técnica acatando a decisão do CMN e da SUSEP. Essas alterações foram homologadas e adotadas pela CVM, por meio da Deliberação CVM 624/10 de 28 de Janeiro de 2010 e pelo CFC, mediante a Resolução CFC 1273/10 de 22 de janeiro de 2010.

Há no meio contábil, uma discussão polêmica que se baseia na afirmativa de que o fluxo de caixa independe na sua elaboração, dos critérios e dos princípios contábeis. $\mathrm{O}$ argumento configura-se como falacioso, por ser desprovido de fundamentação teórica que o justifique e ampare, pois a fonte de consulta das informações do DFC são a escrituração e as demonstrações contábeis. Ambas devem, necessariamente, obedecer aos princípios de contabilidade; aos critérios de avaliação e à classificação de ativos e passivos, de reconhecimento das despesas e receitas; às normas da profissão e os preceitos da Legislação Societária.

A ilustração contendo exemplo simulado de elaboração da DFC, apresentada no Apêndice do Pronunciamento Técnico $n^{\circ} 03$, para facilitar a compreensão do conteúdo normativo utilizou como fonte, dados já publicados pelo IBRACON, (1998, p. 98-105), que foram adaptados no CPC n 03/08, porém deixou de observar os possíveis reflexos que poderiam gerar nos resultados, face à legislação vigente e os princípios contábeis aplicáveis.

O que se percebe é que o conteúdo normativo do Pronunciamento Técnico 03/08, é insuficiente para permitir a divulgação da DFC com informações de maiores qualidades que as que eram geradas pela DOAR.

Cabe então reflexão sobre a seguinte premissa: se as características da DOAR e da DFC elaborada pelo método direto, são complementares, isto é, as informações que uma não evidencia são apresentadas em outra,: então a apresentação de ambas em conjunto, poderia eliminar a maioria das criticas e aumentar a qualidade das informações contábeis para os usuários. 


\section{Statement of cash flow: the controversies of the normative content of Technical Announcement $n^{\circ}$. 03/08}

\section{Abstract}

The requirements of internal and external market resulted from 2002, changes occurring in corporate law Brazilian especially in attempt to promote the development of Brazilian standards in line with international accounting standards adopted in the major securities markets. Among the most important changes include promoted in Law 6,404/76 - Law societies by actions, laws 11,638/09/07 and 11,944, among the changes, the replacement of the statement of changes in financial-DONATE by demonstration of cash flow - DFC. With this, the CPC-Accounting Pronouncements Committee was obliged to precipitate the initiation of discussions and editing statements. It follows also doubts in relation to procedures regarding scope and usefulness of information generated by DFC. The study were: the mandatory disclosure of DFC offers better information published until then? The study was to verify whether the statement of cash flow contributes effectively to production and presentation of accounting information useful and transparent for users of entities. The study showed that the normative content of Technical CPC Pronouncement 03/08 - cash flow statement is a translation with some small changes, IAS 7, statement of cash flows; whereas in replacement of DFC by DONATE showed there was not enough discussion to provide users the best accounting information, useful and transparent. There was the possibility to combine the best features of DONATE and DFC in one Technical Pronouncement, which has not been seized.

Keywords: Cash flow. Useful information. The financial situation

\section{Referências}

BRASIL. Lei $n^{\circ} 11.638$, de 28 de dezembro de 2007. Altera e revoga dispositivos da Lei no 6.404, de 15 de dezembro de 1976, e da Lei no 6.385, de 7 de dezembro de 1976, e estende às sociedades de grande porte disposições relativas à elaboração e divulgação de demonstrações financeiras. Brasília, 2007. Disponível em: <http://www.planalto. gov.br/ccivil_03/_ato2007-2010/2007/lei/111638.htm>. Acesso em: 16 jan. 2010. 
BRASIL. Lei $n^{\circ}$ 6.404, de 15 de dezembro de 1976. Dispõe sobre as Sociedades por Ações. Brasília, 1976. Disponível em: <http://www.planalto.gov.br/ccivil_03/Leis/ L6404consol.htm>. Acesso em: 16 jan. 2010.

BRASIL. Ministério da Fazenda. Circular SUSEP no 379, de 19 de dezembro de 2008. Dispõe sobre alterações das Normas Contábeis a serem observadas pelas sociedades seguradoras, resseguradoras, sociedades de capitalização e entidades abertas de previdência complementar, instituídas pela Resolução CNSP n 86, de 3 de setembro de 2002. Brasília, 2008. Disponível em: <http://www.susep.gov.br/ textos/circ379.pdf>. Acesso em: 16 jan. 2010.

COMISSÃO DE VALORES MOBILIÁRIOS. Deliberação CVM no 547, de 13 de agosto de 2008. Aprovou o Pronunciamento Técnico CPC 03/08 do Comitê de Pronunciamentos Contábeis, que trata da Demonstração dos Fluxos de Caixa DFC. Disponível em: <http://cnb.org.br/CNBV/deliberacoes/dlb624-2010.htm>. Acesso em: 16 jan. 2010.

COMISSÃO DE VALORES MOBILIÁRIOS. Deliberação CVM no 624, de 28 de Janeiro de 2010. Aprova o documento de revisão no 01 referente aos Pronunciamentos CPC 02, CPC 03, CPC 16, CPC 26 e CPC 36 e à Orientação Técnica OCPC 01 emitidos pelo Comitê de Pronunciamentos Contábeis. Brasília, 2010. Disponível em: http:// www.cvm.gov.br/asp/cvmwww/atos/Atos_Redir.asp?Tipo=D\&File=deli624.doc. Acesso em: 04/02/2010.

COMISSÃO DE VALORES MOBILIÁRIOS. Estudo sobre as diferenças e similaridades entre as Normas Internacionais de Contabilidade - IFRS e as Normas e Práticas Contábeis Brasileiras: IAS 7 - demonstração dos fluxos de caixa, 2008. Disponível em: <http://www.eadvisorplus.com/Publication/ vwLUAssets/ Topico_6_-_Relatorio_Padronizado/\$FILE/Topico_6_Relatorio_Padronizado. pdf>. Acesso em: 16 jan. 2010.

COMITÊ DE PRONUNCIAMENTOS CONTÁBEIS. Pronunciamento técnico CPC 03: demonstração dos fluxos de caixa. Brasília, 2008. Disponível em: <http:// www.cpc.org.br/pdf/cpc03.pdf >. Acesso em: 16 jan. 2010.

CONSELHO FEDERAL DE CONTABILIDADE. Resolução CFC nº 1.055/05. Cria o Comitê de Pronunciamentos Contábeis (CPC), e dá outras providências. Brasília, 2005. Disponível em: <http://www.cpc.org.br/pdf/ RES_1055.pdf>. Acesso em: 16 jan. 2010. 
ERNST e YOUNG; FIPECAFI. Manual de normas internacionais de contabilidade: IFRS versus normas brasileiras. 2. ed. São Paulo: Atlas. 2010.

FIPECAFI. Manual de contabilidade das sociedades por ações: aplicável às demais sociedades. 6. ed. São Paulo: Atlas. 2006.

GIASSON, Oldair Roberto et al. Comparação e análise da Demonstração das Origens e Aplicações de Recursos (DOAR) e da Demonstração de Fluxo de Caixa (DFC). In: CONGRESSO BRASILEIRO DE CONTABILIDADE, 16., 2000, Brasília. A contabilidade e o processo de comunicação. Brasília: CFC, 2000. 1 CD-ROM.

IBRACON - INSTITUTO DOS AUDITORES INDEPENDENTES DO BRASIL. Normas internacionais de contabilidade 1997. São Paulo: Ibracon. 1998.

MARQUES, José Augusto Veiga da Costa; BRAGA, Roberto. Demonstração dos fluxos de caixa: uma contribuição à alteração da legislação societária. In: ENANPAD, 25., Campinas, 2001. Anais... Rio de Janeiro: ANPAD, 2001. Disponível em: <http://www.cvm.gov.br/port/snc/Estudosportopicos.asp >. Acesso em: 16 jan. 2010 .

MOURA, Verônica de Miglio; BEUREN, Ilse Maria. Considerações sobre a demonstração do fluxo de caixa e sua relação com a demonstração das origens e aplicações de recursos. In: CONGRESSO BRASILEIRO DE CONTABILIDADE, 16., 2000, Brasília. Profissão contábil: fator de proteção da sociedade. Brasília: CFC, 2000. 1 CD-ROM.

RAMON, Jander. O avanço da transparência: nova lei contábil acelera a convergência das normas brasileiras aos padrões internacionais e desafia um grande número de empresas a se ajustar rapidamente às mais modernas práticas em demonstrações financeiras. Mundo Corporativo, São Paulo, ano 6, n. 19, 1 trimestre 2008.

ROSA, Paulo Moreira da; SILVA, Almir Teles da. Fluxo de caixa: instrumento de planejamento e controle financeiro e base de apoio ao processo decisório. In: CONGRESSO BRASILEIRO DE CONTABILIDADE, 16., 2000, Brasília. Profissão contábil: fator de proteção da sociedade. Brasília: CFC, 2000. 1 CD-ROM.

SANTOS, Ariovaldo dos; LUSTOSA, Paulo Roberto. Demonstração dos fluxos de caixa: uma reflexão sobre a objetividade (ou falta de) do fluxo de caixa. , Informativo Dinâmico IOB, in:Temática contábil. Bol n. 24, São Paulo: IOB, 1999. p. 1-11.

SANTOS, Ariovaldo dos; B. DOAR versus fluxo de caixa. Boletim IOB,. Informativo Dinâmico IOB, in:Temática contábil. out. 1991. São Paulo: IOB. 1991 
SANTOS, Ariovaldo dos; Um novo fluxo de caixa (FASB 95). Boletim IOB, Informativo Dinâmico IOB, in:Temática contábil. Bol n. 13, São Paulo: IOB 1988.

SANTOS, José Luiz dos; SCHMIDT, Paulo. Contabilidade societária. 3. ed. São Paulo: Atlas. 2009.

SANTOS, Luiz Paulo Guimarães dos; FREITAS Sheizi Calheira de. O fluxo de caixa e sua importância no processo de evidenciação das informações contábeis. In: CONGRESSO BRASILEIRO DE CONTABILIDADE, 16., 2000, Brasília. Profissão contábil: fator de proteção da sociedade. Brasília: CFC, 2000. 1 CD-ROM.

\section{Apêndice $A^{2}$}

\section{Demonstração dos Fluxos de Caixa de uma Entidade que não é uma Instituição Financeira}

Este apêndice é apenas ilustrativo e não é parte integrante do Pronunciamento. A finalidade deste apêndice é ilustrar a aplicação do Pronunciamento, para ajudar em seu entendimento.

1. Os exemplos mostram somente os valores do período corrente. Os valores correspondentes do período anterior devem ser apresentados de acordo com o futuro pronunciamento CPC que dará tratamento ao IAS 1 "Presentation of Financial Statements".

2. As informações foram extraídas da demonstração do resultado e do balanço patrimonial e são apresentadas para mostrar quais as origens dos valores que compõem a demonstração dos fluxos de caixa, conforme o método direto e o método indireto. Nem a demonstração do resultado nem o balanço patrimonial estão apresentados em conformidade com os requisitos de divulgação e apresentação das demonstrações contábeis.

2 Refere-se ao Apêndice A do Pronunciamento Técnico CPC 03 - Demonstração dos Fluxos de Caixa - ilustrativo de uma entidade que não é uma Instituição Financeira 
3. As seguintes informações adicionais são também importantes para a preparação da demonstração dos fluxos de caixa:

- todas as ações da controlada foram adquiridas por 590. O valor dos ativos adquiridos e passivos assumidos são apresentados como segue:

\begin{tabular}{|l|r|}
\hline Estoque & 100 \\
\hline Contas a receber & 100 \\
\hline Caixa & 40 \\
\hline Ativo imobilizado (terrenos, fábricas, equipamentos, etc.) & 650 \\
\hline Contas a pagar & 100 \\
\hline Dívida a longo prazo & 200 \\
\hline
\end{tabular}

- 250 foram obtidos mediante emissão de ações e outros 250, por meio de empréstimo a longo prazo;

- a despesa de juros foi de 400, dos quais 170 foram pagos durante o período; 100, relativos à despesa de juros do período anterior, também foram pagos durante o período;

- foram recebidos juros de 200 e dividendos - líquidos de imposto na fonte de 100 - de 200;

- foram pagos durante o período 90 de arrendamento mercantil;

- foram pagos dividendos de 1.200;

- o imposto de renda e a contribuição social a pagar, no início e no fim do período, era de 1.000 e 400, respectivamente; durante o período, fez-se uma provisão de mais 200; o imposto na fonte sobre dividendos recebidos foi de 100;

- durante o período, o grupo adquiriu ativos imobilizados ao custo total de 1.250, dos quais 900 por meio de arrendamento financeiro; pagamentos em dinheiro de 350 foram feitos para compra de imobilizado;

- equipamento do imobilizado ao custo de 80 e depreciação acumulada de 60 foi vendido por 20;

- contas a receber no final de 20X2 incluíam juros a receber de 100. 


\begin{tabular}{|l|r|}
\hline Demonstração Consolidada do Resultado Referente ao Período Findo em 20X2 \\
\hline Vendas & 30.650 \\
\hline Custo de vendas & $(26.000)$ \\
\hline Lucro bruto & 4.650 \\
\hline Depreciação & $(450)$ \\
\hline Despesas de venda e administrativas & $(910)$ \\
\hline Despesa de juros & $(400)$ \\
\hline Renda de investimentos & 500 \\
\hline Prejuízo de câmbio & $(40)$ \\
\hline Lucro líquido antes do imposto de renda e contribuição social & 3.350 \\
\hline Imposto de renda e contribuição social & $(300)$ \\
\hline Lucro líquido & 3.050 \\
\hline
\end{tabular}

\section{Balanço Patrimonial Consolidado em 31 de Dezembro de 20X2}

\section{Ativos}

Caixa e equivalentes de caixa 20X2

Contas a receber

Estoques

Carteira de Investimentos

Ativo imobilizado ao custo

\begin{tabular}{|c|c|}
\hline $20 \times 2$ & $20 \mathrm{X} 1$ \\
\hline 230 & 160 \\
\hline 1.900 & 1.200 \\
\hline 1.000 & 1.950 \\
\hline 2.500 & 2.500 \\
\hline 3.730 & 1.910 \\
\hline$(1.450)$ & (1.060) \\
\hline$\underline{2.280}$ & $\underline{850}$ \\
\hline 7.910 & 6.660 \\
\hline 250 & 1.890 \\
\hline 230 & 100 \\
\hline 400 & 1.000 \\
\hline$\underline{2.300}$ & $\underline{1.040}$ \\
\hline 3.180 & 4.030 \\
\hline 1.500 & 1.250 \\
\hline$\underline{3.230}$ & $\underline{1.380}$ \\
\hline 4.730 & 2.630 \\
\hline 7.910 & 6.660 \\
\hline
\end{tabular}

Depreciação acumulada

Ativo imobilizado líquido

Total do ativo

Passivos

Contas a pagar

Juros a pagar

IR e contribuição social a pagar

Dívida a longo prazo

Total do passivo

Patrimônio Líquido

Capital social

Lucros acumulados

Total do patrimônio líquido 


\section{Demonstração dos Fluxos de Caixa pelo Método Direto 20X2}

Fluxos de caixa das atividades operacionais

Recebimentos de clientes 30.150

Pagamentos a fornecedores e empregados (27.600)

Caixa gerado pelas operações 2.550

Juros pagos (270)

Imposto de renda e contribuição social pagos (800)

Imposto de renda na fonte sobre dividendos recebidos $\underline{(100)}$

Caixa líquido proveniente das atividades operacionais 1.380

Fluxos de caixa das atividades de investimento

Aquisição da controlada X líquido do caixa incluído na aquisição (Nota A) (550)

Compra de ativo imobilizado (Nota B) (350)

Recebido pela venda de equipamento 20

Juros recebidos 200

Dividendos recebidos $\underline{200}$

Caixa líquido usado nas atividades de investimento (480)

Fluxos de caixa das atividades de financiamento

Recebido pela emissão de ações 250

Recebido por empréstimo a logo prazo 250

Pagamento de passivo por arrendamento (90)

Dividendos pagos* ${ }^{\star}(1.200)$

Caixa líquido usado nas atividades de financiamento (790)

Aumento líquido de caixa e equivalentes de caixa 110

Caixa e equivalentes de caixa no início do período (Nota C) $\underline{120}$

Caixa e equivalentes de caixa ao fim do período (Nota C) 230

$\left.{ }^{*}\right)$ - Esse valor também pode ser apresentado no fluxo de caixa das atividades operacionais. 


\section{Demonstração dos Fluxos de Caixa pelo Método Indireto 20X2}

\section{Fluxos de caixa das atividades operacionais}

Lucro líquido antes do imposto de renda e contribuição social 3.350

Ajustes por:

Depreciação 450

Perda cambial 40

Renda de investimentos (500)

Despesas de juros $\underline{400}$

\subsection{0}

Aumento nas contas a receber de clientes e outros (500)

Diminuição nos estoques 1.050

Diminuição nas contas a pagar - fornecedores (1.740)

Caixa proveniente das operações 2.550

Juros pagos (270)

Imposto de renda e contribuição social pagos (800)

Imposto de renda na fonte sobre dividendos recebidos $\underline{(100)}$

Caixa líquido proveniente das atividades operacionais 1.380

Fluxos de caixa das atividades de investimento

Aquisição da controlada X menos caixa líquido incluído na aquisição (Nota A) (550)

Compra de ativo imobilizado (Nota B) (350)

Recebimento pela venda de equipamento 20

Juros recebidos 200

Dividendos recebidos 200

Caixa líquido usado nas atividades de investimento (480)

Fluxos de caixa das atividades de financiamento

Recebimento pela emissão de ações 250

Recebimento por empréstimos a longo prazo 250

Pagamento de obrigação por arrendamento (90)

Dividendos pagos* (1.200)

Caixa líquido usado nas atividades de financiamento (790)

Aumento líquido de caixa e equivalente de caixa 110

Caixa e equivalente de caixa no início do período $\underline{120}$

Caixa e equivalente de caixa no fim do período 230 


\section{Notas Explicativas sobre a Demonstração dos Fluxos de Caixa (métodos direto e indireto)}

\section{A. Aquisição de Subsidiária}

Durante o período, o Grupo adquiriu a controlada X. O valor dos ativos adquiridos e dos passivos assumidos é apresentado a seguir:

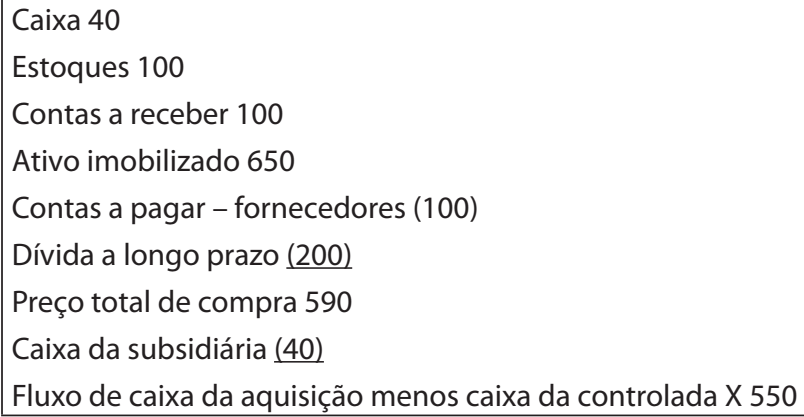

\section{B. Ativo Imobilizado}

Durante o período, o Grupo adquiriu ativo imobilizado com um custo total de 1.250, dos quais 900 por meio de arrendamento financeiro. Pagamentos em dinheiro de 350 foram feitos para aquisição de imobilizado.

\section{Caixa e Equivalentes de Caixa}

Caixa e equivalentes de caixa consistem em numerário disponível na entidade, saldos em poder de bancos e aplicações financeiras de curto prazo. Caixa e equivalentes de caixa incluídos na demonstração dos fluxos de caixa compreendem:

20X2 20X1
Caixa e saldos em bancos 4025
Aplicações financeiras de curto prazo 190135
Caixa e equivalentes de caixa 230160
Efeito de oscilações nas taxas cambiais - (40)
Caixa e equivalentes de caixa ajustados 230 120

Caixa e equivalentes de caixa no fim do período incluem depósitos em banco de 100, mantidos por uma controlada, os quais não são livremente remissíveis à matriz por motivos de restrições cambiais.

O Grupo tem linhas de crédito disponíveis para utilização no valor de 2.000, dos quais 700 poderão ser utilizados somente para expansão futura. 
40 | Univ. Gestão e TI, Brasília, v. 1, n. 1, p. 1-40, jan./jun. 2011

\section{Informação por Segmentos}

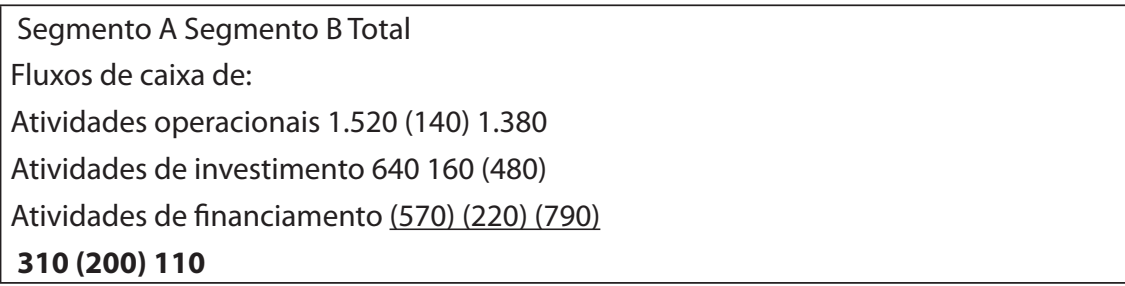

\section{Apresentação Alternativa (Método Indireto)}

Como alternativa, numa demonstração dos fluxos de caixa pelo método indireto, o lucro operacional, antes das mudanças no capital de giro, é, às vezes, demonstrado como segue:

Receitas, excluída a renda de investimentos 30.650

Despesas operacionais, excluída a depreciação (26.910)

Lucro operacional antes das mudanças no capital de giro 3.740 